\title{
Editorial
}

\section{Specificity questions concerning the clone 33 anti-fas ligand antibody}

\author{
JR Baker Jr, and JD Bretz ${ }^{1}$ \\ ${ }^{1}$ Center for Biologic Nanotechnology, University of Michigan, Ann Arbor, MI \\ 48109-0648, USA \\ * Corresponding author: JR Baker Jr, Center for Biologic Nanotechnology, \\ University of Michigan, Ann Arbor, MI 48109-0648, USA. Tel: 001734647 \\ 2777; Fax: 001734936 2990; E-mail: jbakerjr@umich.edu
}

Edited by JD Bretz

Two letters presented in the current issue of Cell Death Differentiation raise concerns about the specificity of a reagent used to analyze the expression of FasL on cells. The antibody under question, clone 33, is marketed by Transduction Laboratories (Lexington, KY, USA) which is now owned by Pharmingen (itself a subsidiary of Becton Dickenson). While other antibodies against FasL have been questioned for not being able to recognize the protein under certain conditions, ${ }^{1}$ Clone 33 is unusual because it has been reported to provide false positive identification of FasL in cells. ${ }^{2,3}$ Clone 33 also is unique because it has been used to document FasL expression in a number of prominent publications. ${ }^{4-6}$ Although the questions concerning the specificity of clone 33 were raised publicly over a year ago, the antibody continues to be used by investigators and has proponents defending its use. Nowhere is the controversy more clearly presented than in the two letters in this issue, where seemingly contradictory data on the specificity of this antibody are presented! In this Editorial, we will review the background of clone 33, analyze the data presented in the two letters and come to a consensus on the appropriate use of this reagent.

\section{Prior concerns raised about clone 33}

Clone 33 has been used in many, diverse studies examining the role of FasL expression in various cells and physiologic processes. ${ }^{4-8}$ Enthusiasm for several of these studies came, in part, from initial findings suggesting that FasL expression was potentially important in preventing graft rejection and promoting tolerance of privileged sites such as the cornea and testis. $^{9,10}$ While other studies have suggested that FasL expression alone is not enough to thwart an immune response, ${ }^{11}$ it has been suggested that FasL is important in a spectrum of immune activities. These include the ability of tumors to evade immune surveillance and the pathophysiology of Graves' disease. 5,7,12 Because initially there were few reagents commercially available to assay for FasL protein, one antibody (clone 33) was employed for much of this work.

Our interest in this antibody was generated by studies from Giordano published in Science in July 1997. ${ }^{8}$ This work suggested that thyroid cells have constitutive expression of FasL and the induction of Fas antigen expression by inflammatory cytokines leads to thyrocyte 'fratricide' due to ligand-receptor interactions. The authors suggested this was the basis for thyroid cell destruction in thyroiditis. We were confused by these findings because others and we had observed constitutive expression of Fas antigen on normal thyroid cells. ${ }^{13}$ The simultaneous, constitutive expression of FasL therefore should have led to thyroid destruction even in normal tissue. We decided to assay for FasL mRNA expression in normal thyroid cells and did not observe it either by nuclease protection assay or RT-PCR. Surprisingly, when Western blots of thyroid lysates were probed for FasL protein, one of the three antibodies we used (clone 33 ) gave strong signals at the appropriate molecular weight $(37 \mathrm{kDa})$ of FasL. Since our findings were inconsistent, we reported that the specificity of this antibody was in question. ${ }^{2}$ Eibel and colleagues, working entirely independently came to the same conclusion through similar studies ${ }^{3}$ and both reports were published simultaneously. While the original authors did not re-evaluate thyroid cells, they responded that some cell lines, clone 33 appeared to detect FasL by flow cytometry. ${ }^{14}$ However, they did not document the absolute specificity of the antibody for FasL. Thus, the specificity of clone 33 was not resolved and investigators have continued to use this antibody to identify FasL in various scientific applications.

\section{Information in current letters}

The current letters were written to attempt to clarify the specificity of FasL recognition by clone 33 . Herr and colleagues $^{15}$ attempt to address this situation in the first letter. These investigators examined expression of FasL in a clone of 293 cells that were transfected with the full-length cDNA for FasL. They conclude that clone 33 recognizes recombinant full length FasL in both denaturing (Western blot) and non-denaturing conditions (immunoprecipitation). However, a very different pattern of recognition was observed with purified, recombinant FasL protein that lacked the intracellular portion of the protein. With this truncated protein, clone 33 only bound under non-denaturing conditions. There were also other inconsistencies with the clone 33 antibody, as it had 'high' affinity for the full length FasL in Western blots but low affinity for the protein when used in flow cytometry. In addition, unlike the G-247-4 or the NOK1 antibodies, clone 33 only recognized a single molecular weight band in Western blots and did not recognize other bands that appeared to be the result of alternative glycosylation of FasL. The authors suggest that these inconsistencies are the result of masking of the clone 33 epitope due to glycosylation or the affinity tag (on the recombinant, truncated FasL). However, this explanation is not satisfying. If the affinity of clone 33 for FasL in Western blots was higher than the other antibodies, it should recognize all of the molecular weight forms of the full-length protein recognized by the other antibodies. If glycosylation masking of the clone 33 epitope is a problem, the antibody should at least recognize the 
lower molecular weight forms of FasL that presumably have less glycosylation than the band it recognizes. More importantly, if the full-length FasL experiments are correct in suggesting that clone 33 has higher affinity for denatured Fas $L$ than native protein on cells, it suggests the antibody identifies a linear epitope. Why then does it only recognize the truncated FasL protein under non-denaturing conditions? Also, while an affinity tag might mask an epitope by folding over it, wouldn't this be more likely to occur under non-denaturing conditions? Thus, Herr's studies raise many contradictions about the specificity of the clone 33 antibody.

In response to Herr's letter, Fiedler and Eibel ${ }^{16}$ performed additional experiments examining clone 33 binding also using FasL transfected 293 cells. Their results are similar to Herr in that clone 33 only recognizes one band on Western blots of cell lysates (in comparison to other FasL antibodies). They also found that clone 33 can immunoprecipitate FasL in non-denaturing conditions. However, unique to these studies clone 33 also blotted a band in lysates of non-transfected 293 cells that was indistinguishable from the FasL transfected cells. The investigators then performed 2-D gel analysis and immunoblots with three FasL antibodies and found that clone 33 does not recognize the same protein as the other FasL antibodies. This indicates that while clone 33 can recognize FasL in native conformation, it recognizes another protein expressed in these cells under denaturing conditions.

Can the contradictions between these two studies be resolved? The greatest difference is the lack of a band in Herr's Western blots of non-transfected 293 cells with clone 33. This could be the result of differences in the amount of cell lysate placed in each well of the blot. Additionally, the 293 cell line has been propagated by many individuals, and as such its nature could change in certain subclones. Thus it is possible that Herr's cells may have lost expression of the cross-reactive protein. While one might argue that Eibel's control cells might be accidentally transfected with FasL, this is unlikely given the $2 \mathrm{D}$ gel analysis. When examining both investigators' studies, the different staining patterns for clone 33 and the other Fas antibodies are most readily explained by recognition of different proteins under reducing conditions. It would also account for the apparent high affinity of clone 33 for FasL in Western blots of whole cell lysates since the cross-reactive protein is present in much higher concentration than the transfected FasL. Importantly, the findings that the purified, recombinant, truncated FasL is not recognized in denaturing conditions supports the concept that the cross reactive protein is the only protein clone 33 recognizes in Western blots. If clone 33 only binds FasL under non-reducing conditions, the lower affinity of clone 33 observed in the flow cytometry studies now corresponds to the antibody's actual affinity for FasL. The specific binding of FasL seen in the immunoprecipitation studies with clone 33 is consistent with this scenario since FasL would be detected under nondenaturing conditions. In addition, the second antibody used in the immunoprecipitation assays would not recognize the cross-reacting protein, therefore preventing its appearance in the precipitate. Finally, since the flow cytometry studies with 293 cells demonstrate low background staining, this suggests that the cross reactive protein is only recognized under denaturing conditions. Thus, it appears that under denaturing conditions clone 33 recognizes a protein that is $37 \mathrm{kDa}$ in size but is not FasL.

\section{Conclusion}

So, where does this leave the clone 33 antibody? Both letters provide information that clone 33 will bind FasL under certain conditions. It is possible that further studies to epitope map using the clone 33 privde the basis to would clarify the binding site and identify a cross-reactive protein. This might make clone 33 useful for identifying FasL in some limited circumstances. However, both letters demonstrate the terrible inconsistencies that arise in trying to analyze data from an antibody that recognizes more than one protein. Fiedler and Eibel's 2D blots provide conclusive data that clone 33 binds to a second, cellular protein other than FasL at least in some cells under reducing conditions. In light of this, it is simply inconceivable to think that clone 33 is a generally useful reagent for identifying FasL and several actions need to be taken. This information should be widely distributed so investigators can take appropriate precautions with this reagent. Unfortunately, selling this antibody without providing any information on potential problems (as is done in the current Transduction Laboratories catalogue) encourages inappropriate use and impedes scientific progress in this field. In addition, it is important that all investigators who have used clone 33 to identify FasL in cells should confirm their findings with more specific reagents. For example, while Debatin and his colleagues (authors of the first letter) have produced extensive and very elegant studies on Fas, they now must re-evaluate their findings for clone 33-induced inconsistencies. Finally, it may be appropriate to call on the makers of clone 33 to remove this antibody from the market. In doing this, they enhance the scientific process and encourage the use of more specific reagents.

\section{References}

1. Smith D, Sieg S and Kaplan D (1998) J. Immunol. 160: 4159-4160

2. Stokes TA, Rymaszewski M, Arscott PL, Wang SH, Bretz JD, Bartron JL and Baker Jr JR (1998) Science 279: 2015a

3. Fiedler P, Schaetzlein CE and Eibel H (1998) Science 279: 2015a

4. KienerPA, Davis PM, Starling GC, Mehlin C, Klebanoff SJ, Ledbetter JA and Liles WC (1997) J Exp Med 185: 1511-1516.

5. Rabinowich H, Reichart TE, Kashii Y, Gastman BR, Bell MC and Whiteside TL (1998) J Clin Invest 101: 2579-2588.

6. Moalem G, Monsonego A, Shani Y, Cohen IR and Schwartz M (1999) FASEB J. 13: $1207-1217$.

7. Mo YY and Beck WT (1999) Mol. Pharmacol. 55: 216-222.

8. Giordano C, Stassi G, De Maria R, Todaro M, Richiusa P, Papoff G, Ruberti G, Bagnasco M, Testi R and Galluzzo A (1997) Science 275: 960-963.

9. Griffiths TS, Brunner T, Fletcher SM, Green DR and Ferguson TA (1995) Science 270: 1189-1191.

10. Bellgrau H, Gold D, Selawry H, Moore J, Franzusoff A and Duke RC (1995) Nature 377: $630-632$.

11. Chen J, Sun $Y$ and Nabel GJ (1998) Science 282: 1714-1717.

12. Hiromatsu Y, Hoshino T, Yagita H, Koga M, Sakisaka S, Honda J, Yang D, Kayagaki N, Okumura K and Nonaka K (1999) J. Clin. Endocrinol. Metabl. 84: 2896-2902.

13. Arscott PL, Knapp J, Rymaszewski M, Bartron JL, Bretz JD, Thompson NW and Baker Jr JR (1997) Endocrinology 138: 5019-5027.

14. Papoff G, Stassi G, De Maria R, Giordano C, Galluzzo A, Bagnasco M, Ruberti G and Testi R (1998) Science 279: 2015a.

15. Herr I, Posovsky C, Boehler T and Debatin KM (2000) Cell Death Differ 7: $129-$ 130 (letter).

16. Fiedler $P$ and Eibel H (2000) Cell Death Differ 7: 126-128 (letter). 